\title{
IAU100 Activities and Recent Developments in Turkish Astronomy
}

\author{
Sinan Aliş*1,2,3 \\ ${ }^{1}$ Department of Astronomy and Space Sciences, Faculty of Science, Istanbul University, Istanbul, Turkey \\ ${ }^{2}$ Istanbul University Observatory Research and Application Center, Istanbul, Turkey \\ ${ }^{3}$ Turkish Astronomical Society (TAD)
}

\begin{abstract}
In this paper, astronomy activities in Turkey in the year of 2019 are summarized. Especially, public outreach activities and teacher training programs in the framework of IAU 100 celebrations are given. Current status of the Eastern Anatolia Observatory and Turkish Space Agency are also summarized. Finally, recently established working group on the legislation for the light pollution is introduced.
\end{abstract}

Keywords: astronomy: general, observatories, miscellaneous

\section{IAU 100 Events}

2019 marks the 100th year since the International Astronomical Union has been established. In order to create a global public awareness and attraction to science but with focus in astronomy, IAU has organized several projects in different themes. Turkey took part on these events through the coordination of the Turkish Astronomical Society (TAD) and the National Outreach Coordinator (NOC). Information about the global events and their listing were given in the IAU100 website ${ }^{1}$ whereas local events in Turkey are presented in the TAD's special website devoted for IAU $100^{2}$.

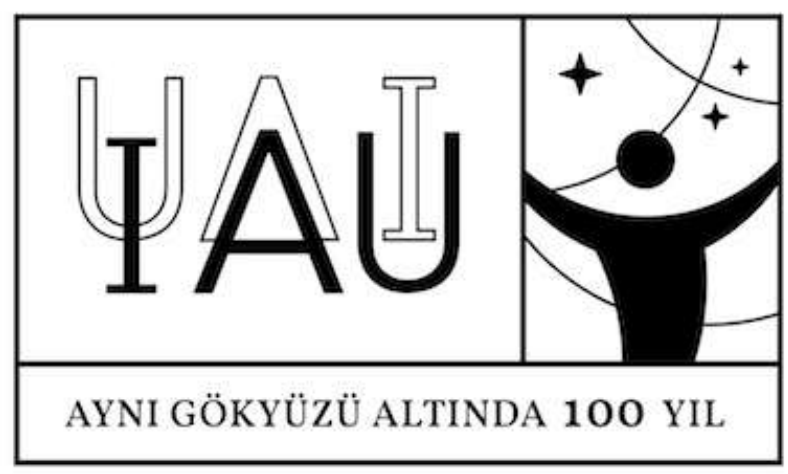

Figure 1: IAU 100 logo in Turkish.

One of the most participated event amongst other IAU 100 activities was the $\mathbf{1 0 0}$ Hours of Astronomy. This event was designed to be held continuously through the globe during 10-13 January, 2019. Almost 30 individual events have been registered for this project with a total participants of 4000. Some event posters are given in Figure 2 and some representative photos taken during 100 Hours of Astronomy events are given in Figure 3.

*salis@istanbul.edu.tr

${ }^{1}$ https://www.iau-100.org/

${ }^{2}$ http://iau100.tad.org.tr 

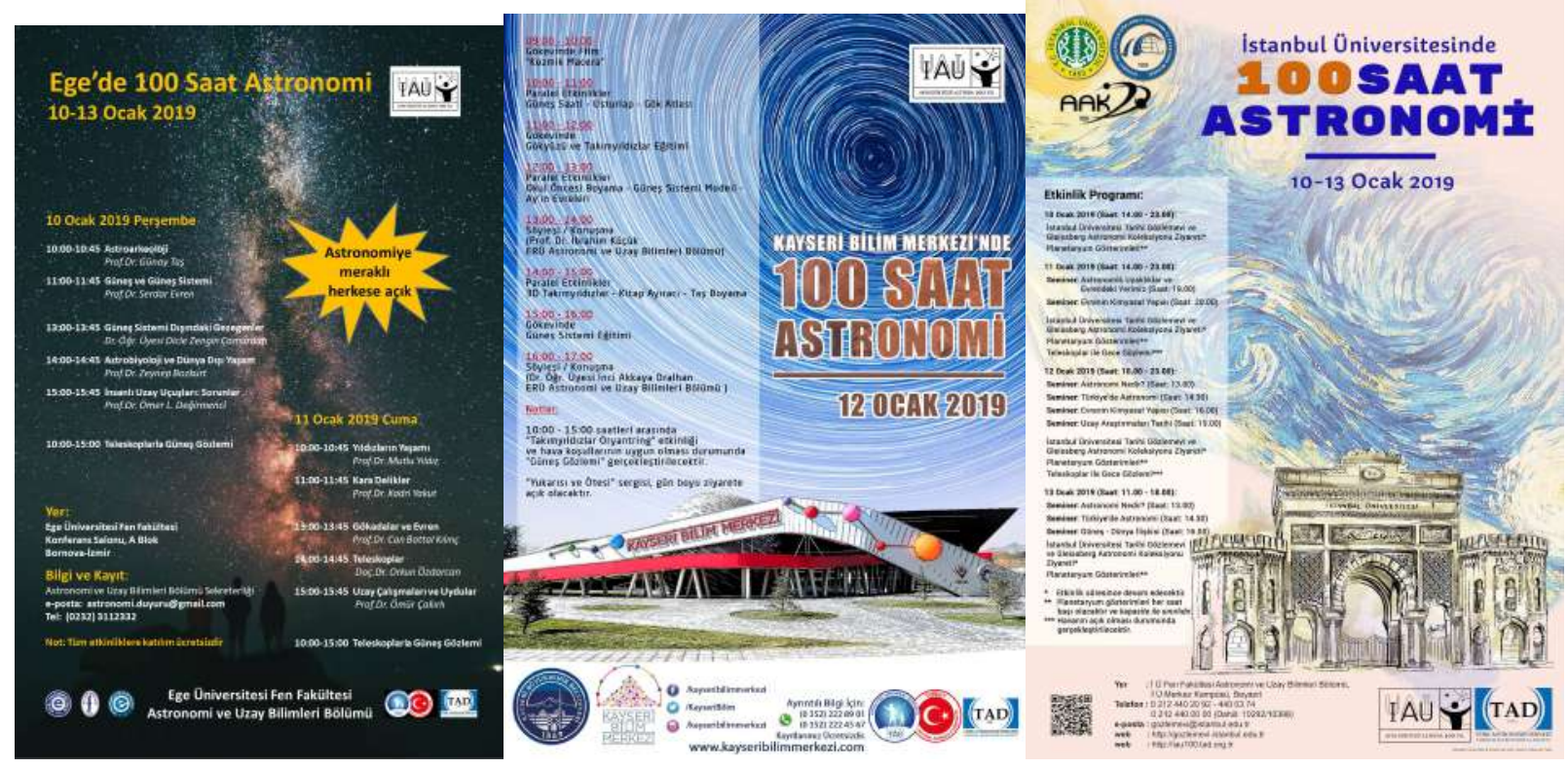

Figure 2: Sample of 100 Hours of Astronomy event posters. From left to right; events organized by Ege, Erciyes and Istanbul Universities, respectively.

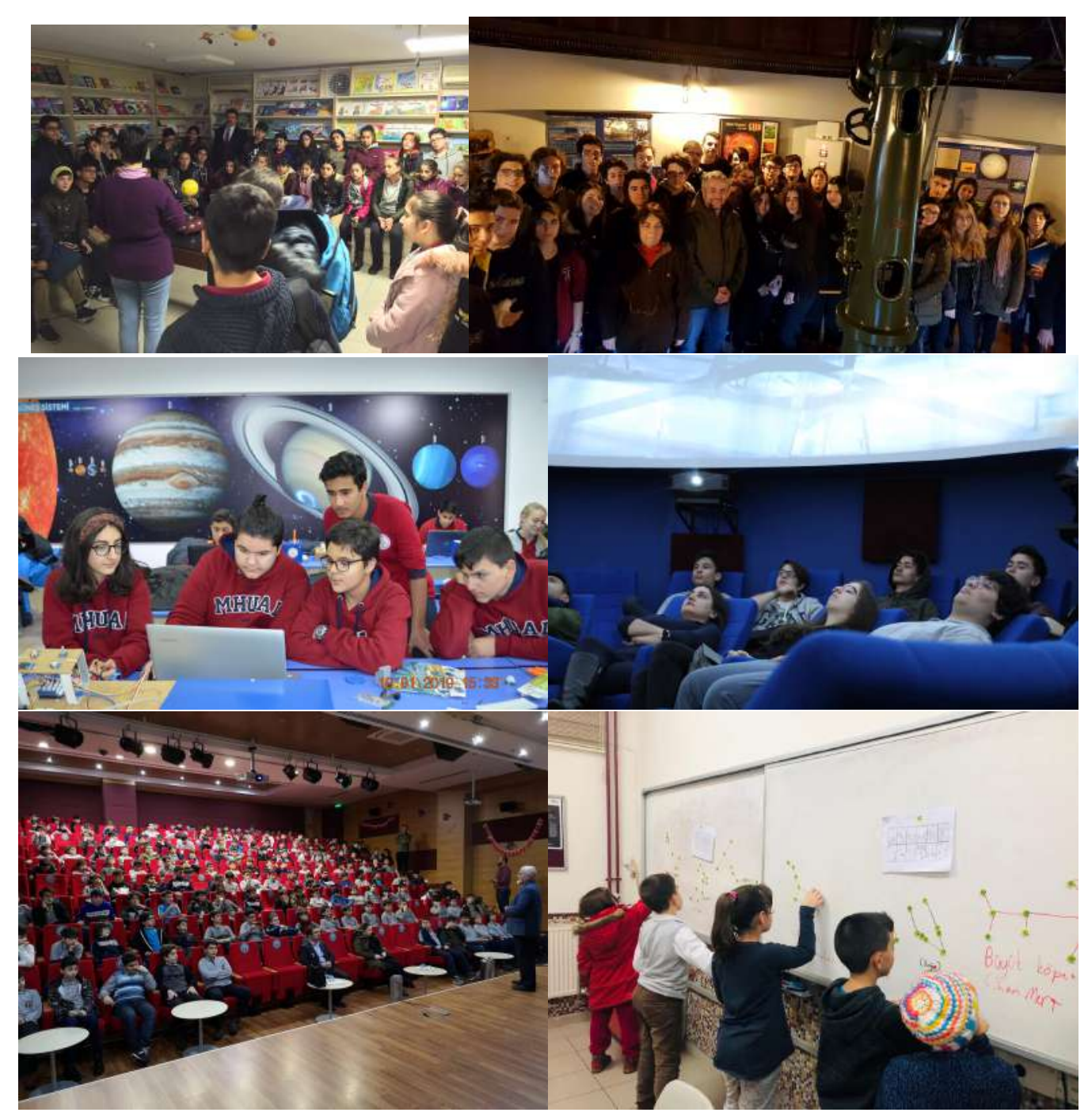

Figure 3: Some photos taken during the 100 Hours of Astronomy events. 
IAU had organized an exoplanet naming campaign in 2015 to name 19 planets. Taking the opportunity to celebrate it's 100th anniversary, IAU launched another version of NameExoWorlds campaign which almost 100 countries have participated. Each country supposed to name an exoplanet and the host star which revolves around it. WASP-52 in the constellation Pegasus assigned to Turkey together with it's planet WASP-52b.

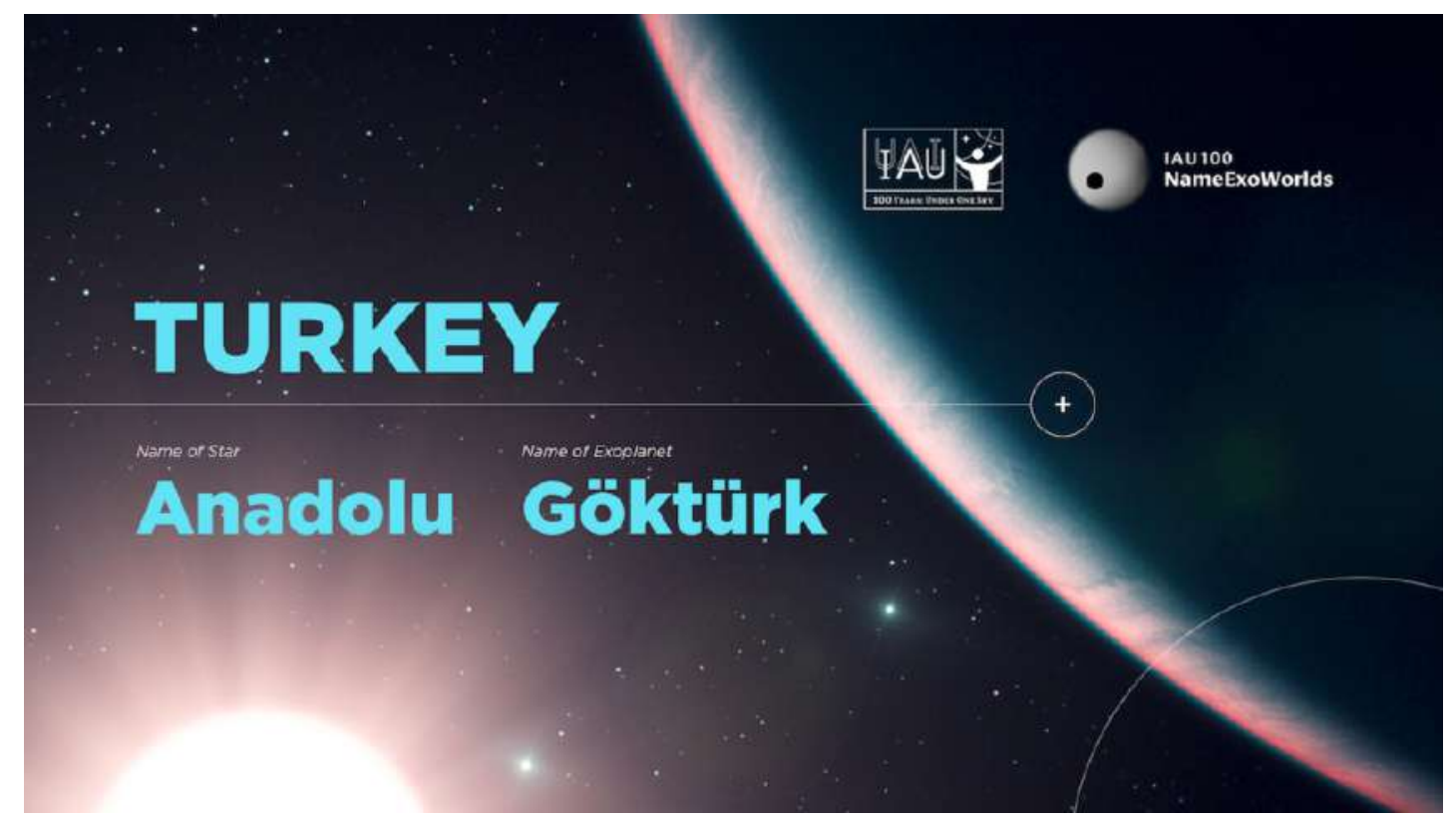

Figure 4: Result of the IAU 100-NameExoWorlds campaign for Turkey. Anadolu and Göktürk were selected as the proper names for WASP-52 and its planet, respectively.

A nationwide campaign carried out by the Turkish Astronomical Society which involves all educational, scientific and related institutions. Each institution supposed to propose a name for star and a name for the planet based on their internal selection. Nearly 300 submissions have been made to the campaign. A national selection committee consisting of seven distinguished researchers and chaired by the IAU Turkey National Outreach Coordinator, has evaluated the submissions. A short list of names, after filtered out already existing names of celestial objects and names that are not complying the rules, voted by the members of the society. The committee decided to propose three couples (one main and two back-ups) of proposition in the end of this process. Following the examination of the IAU NameExoWorlds Executive Committee, Anadolu and Göktürk have been approved to be the proper names for the star WASP-52, and for the exoplanet WASP-52b, respectively.

Besides 100 Hours of Astronomy, Open Astronomy Schools, Women and Girls in Astronomy, Moon Landing 50, and IAU 100 NameExoWorlds projects were the activities that many people engaged and followed. For the IAU 100 celebrations, more than 60 individual event have been organized in Turkey.

ISTEK Belde Schools Astronomy Museum ${ }^{3}$ hosted an exhibition for the 50th anniversary of the Moon landing. Astronomy Museum in the school is the first and only astronomy museum within a K12 educational institution. Moon Landing exhibition lasted between the dates 16 April 2019-30 December 2019 and visited by 7661 people according to the Astronomy Museum's records.

As the final event for the IAU100 framework, 30th anniversary of the "Pale Blue Dot" image was also celebrated. Author of the present paper gave a public talk in Istanbul University for an audience of 200 people.

\footnotetext{
${ }^{3}$ http://www.astronomimuzesi.com
} 


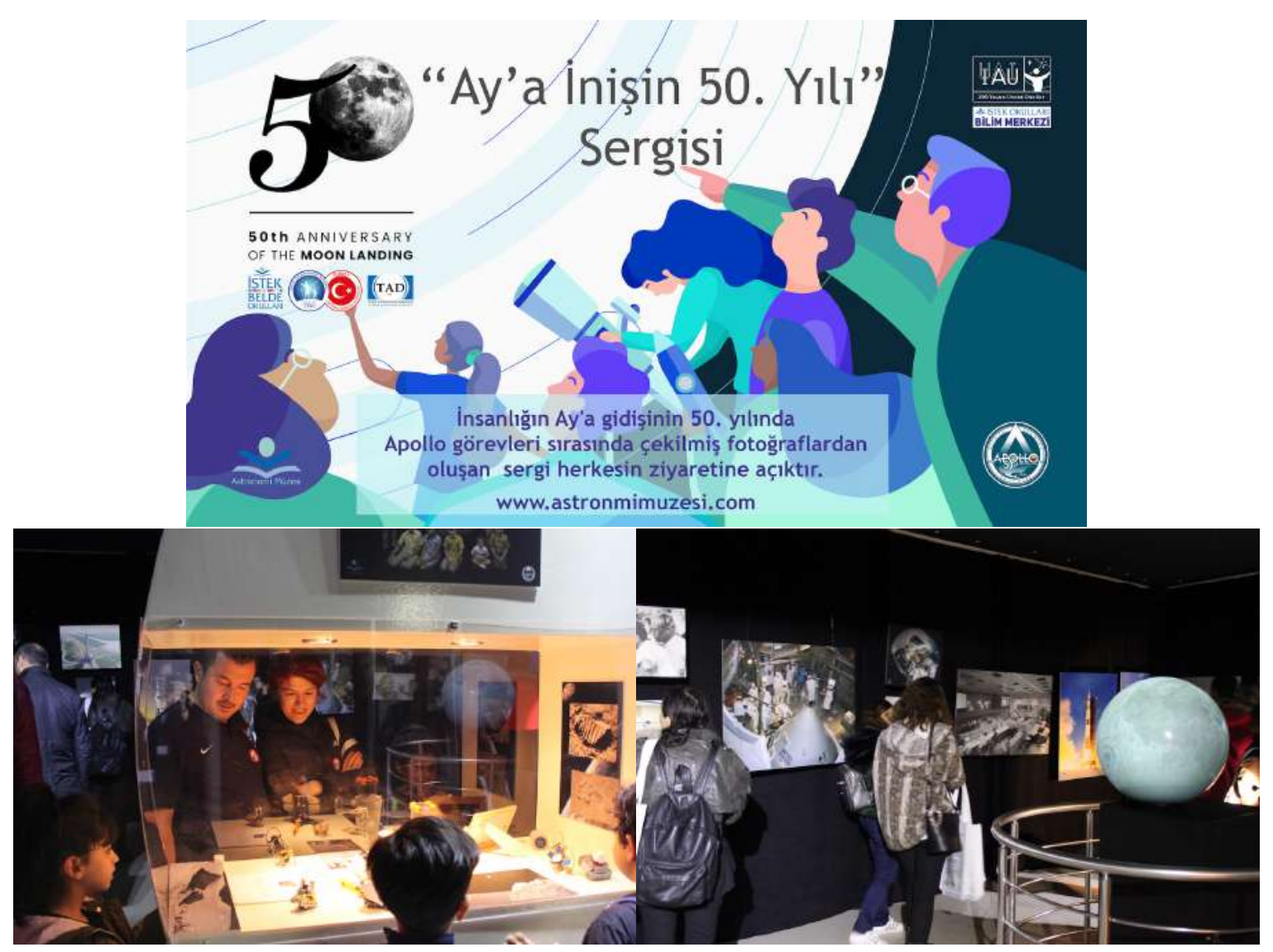

Figure 5: Exhibition organized by ISTEK Belde Schools Astronomy Museum for the 50th anniversary of the Moon Landing.

\section{Teacher Training Programs}

Turkish Astronomical Society's Public Outreach Commission, known as AstroBilgi ${ }^{4}$, organizes regular teacher training programs countrywide as well as special programs for childen. In 2019, TADAstroBilgi organized 10 different events for teachers. Almost 600 teachers have participated to these training programs. Some of the event posters are given in Figure 7.

The event held in the city of Duzce between 3-5 May 2020 was supported by the IAU100 Open Astronomy Schools project.

Istanbul University Department of Astronomy and Space Sciences started a special teacher training program in collaboration with Istanbul Branch of the Ministry of Education (see Figure 8). This program lasts 10 weeks for 40 teachers. Participants for the program selected based on the their field and interest that is shown with an essay. A curriculum for the teachers has been designed by the astronomy department together with counsels from the Ministry of Education. This intense training program aims to improve the knowledge of K12 school teachers who especially teach astronomy or conduct astronomy activities in schools.

\footnotetext{
${ }^{4}$ http://www.astrobilgi.org
} 


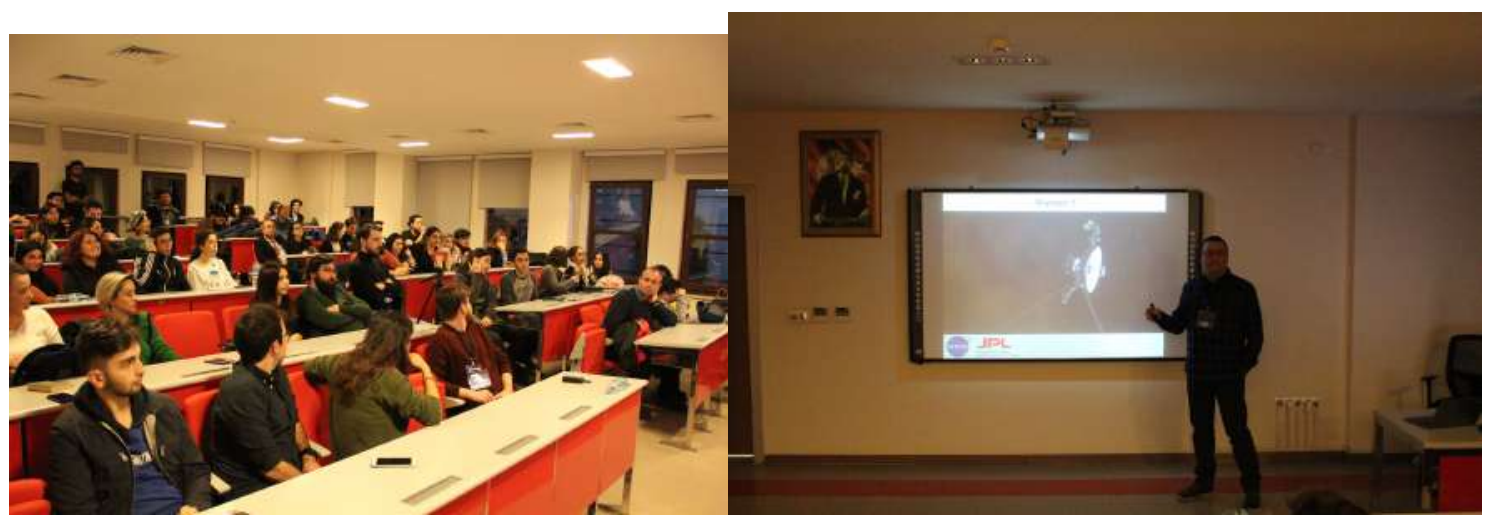

Figure 6: Photos from the Pale Blue Dot event in Istanbul University.

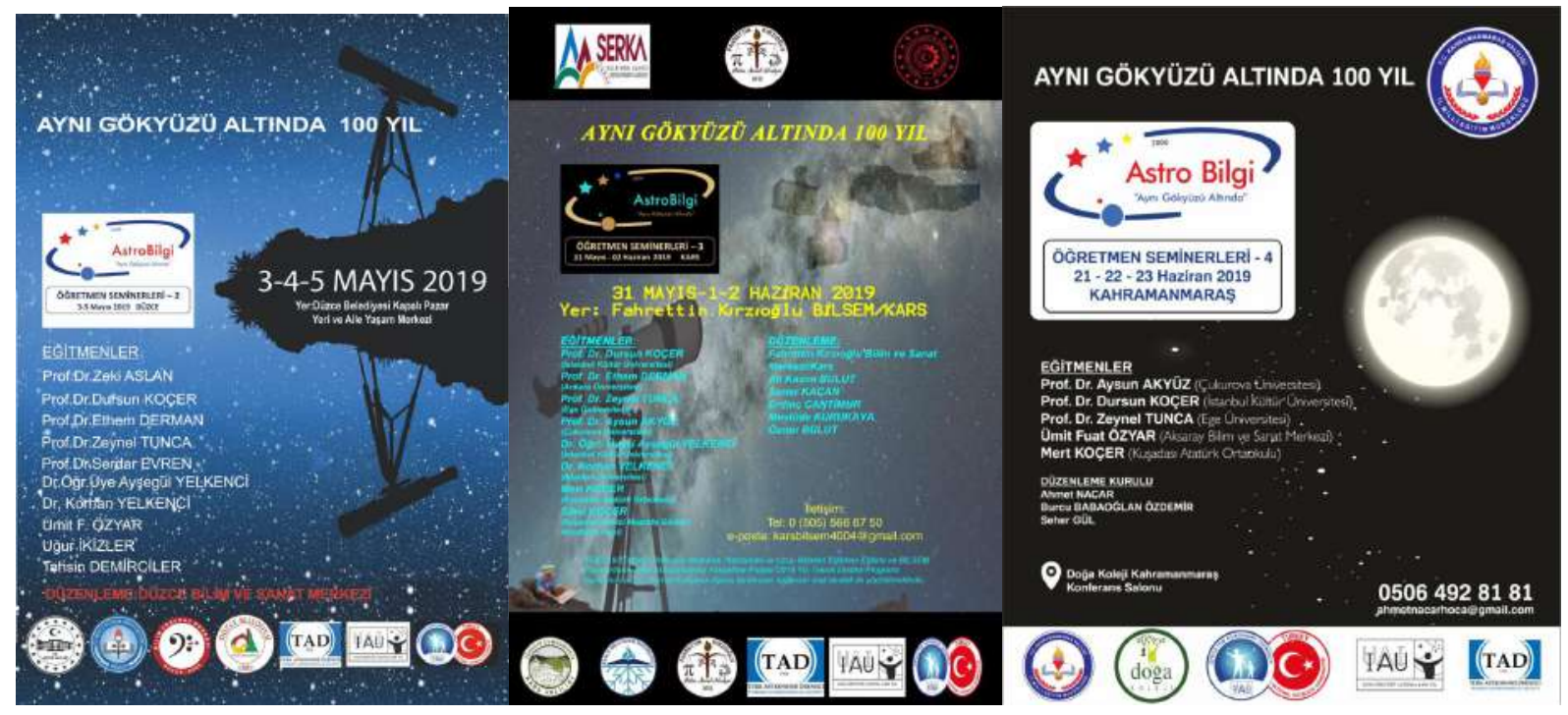

Figure 7: Sample teacher training events that have been organized by AstroBilgi, Turkish Astronomical Society's Public Outreach Commission. Examples here for the events in the cities Düzce, Kars, and Kahramanmaraş, respectively.

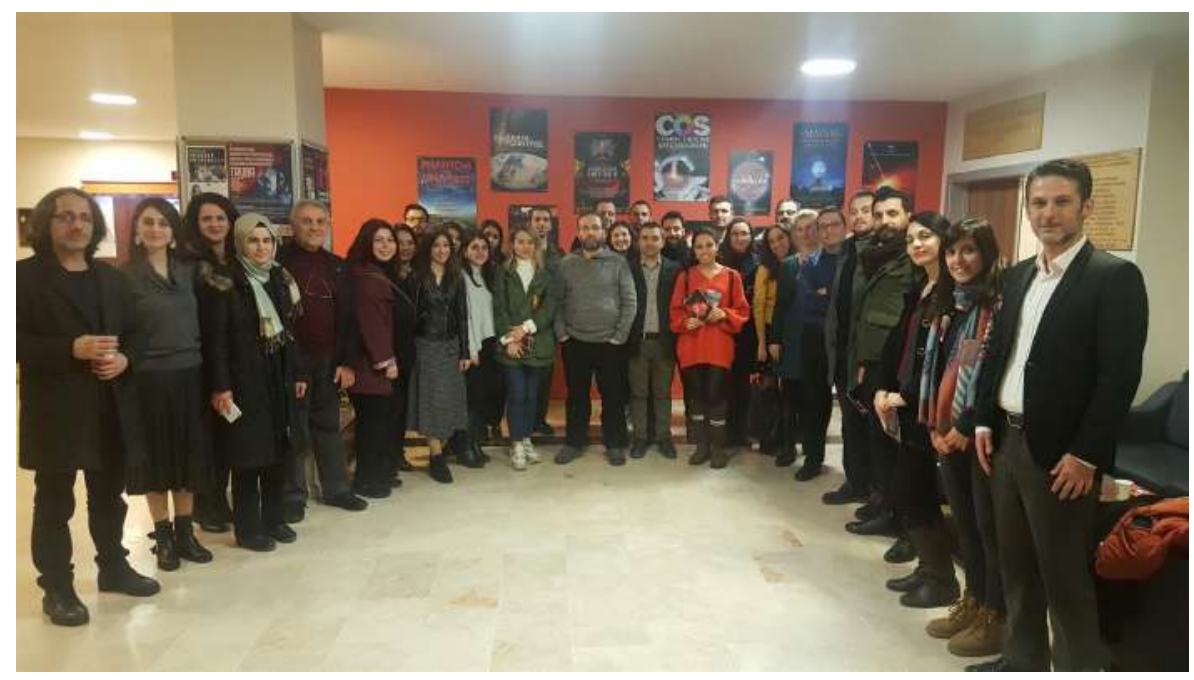

Figure 8: Teacher training program organized by Istanbul Branch of Ministry of Education together with Istanbul University, Department of Astronomy and Space Sciences. 


\section{Turkish Space Agency}

Long awaited state organization Turkish Space Agency officially established on 13 December 2018. Agency is dependent to the Ministry of Industry and Technology which all science and technology related state institutions are also part of. Agency was busy with establishing its organizational structure in the first half of 2019. Current President of the Turkish Space Agency is Mr. Serdar Hüseyin Ylldırım. Mr. Ylldırım leads to the agency and the executive board which has seven members, including the Director of the TÜBİTAK National Observatory ${ }^{5}$. Members of the Executive Board can be seen in Figure 9 with the Minister of Industry and Technology, Mr. Mustafa Varank.

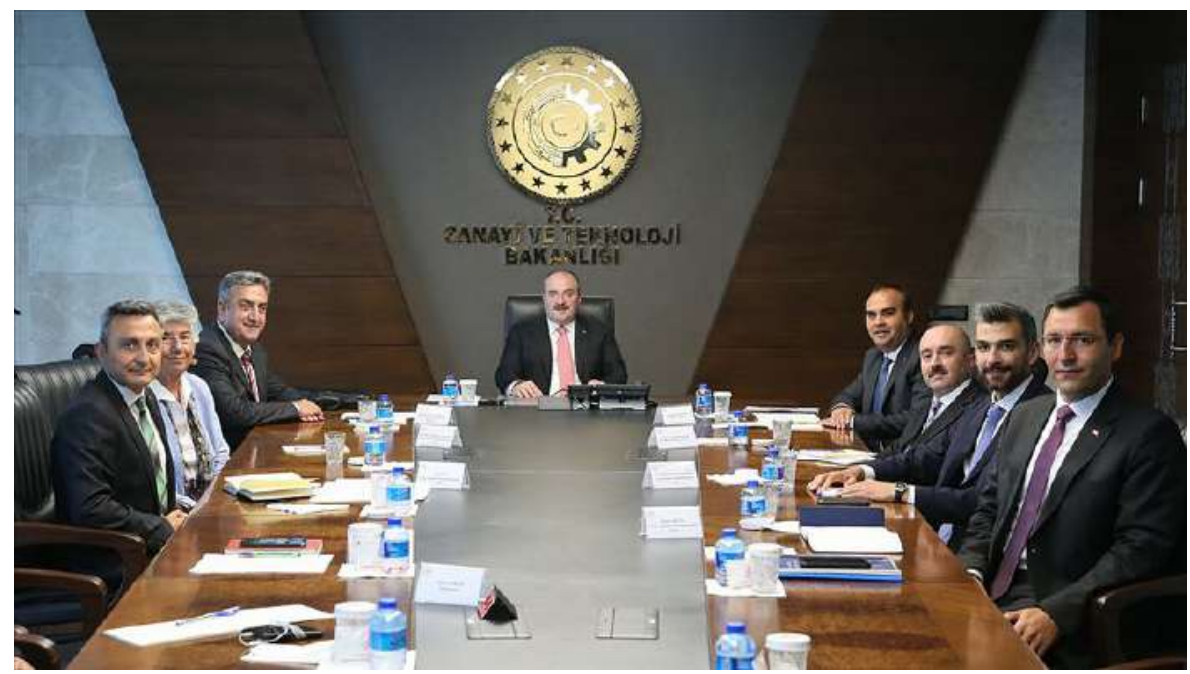

Figure 9: The first Executive Board meeting of the Turkish Space Agency took place on the 3rd of September, 2019.

Turkish Space Agency is responsible at first place to develop a national space program. Some of the main duties of the agency are as follows:

- Develop remote sensing applications; for security, for agriculture, and for disasters.

- Develop international collaborations; especially with other space agencies and related organizations

- Coordinate all activities at national level in accordance with international respective bodies.

- Coordinate and develop aerospace technologies.

- Coordinate human resources and related infrastructures for developing aerospace technologies.

- Cooperate with related industries for the sake of aerospace technologies.

\section{Updates for the DAG Telescope}

Turkey's largest science project is currently on the track. Building of the Eastern Anatolia Observatory continues. In $2019,80 \%$ of the enclosure construction has been completed by the Italian company $E I E^{6}$ at the site. In parallel to the enclosure, the construction of the building is ongoing. Almost $90 \%$ of the main building have also been completed by the Turkish company DAB Construction ${ }^{7}$.

Nearly all necessary infrastructures for the observatory are in place such as electricity, fiber internet, dirt road. Asphalt road will be completed during 2020-2021 period before the mirror has been transported.

\footnotetext{
${ }^{5}$ http://tug.tubitak.gov.tr

${ }^{6} \mathrm{http}: / / \mathrm{www} . e i \mathrm{e} . \mathrm{it} / \mathrm{en}$

${ }^{7}$ http://www.dabinsaat.com
} 


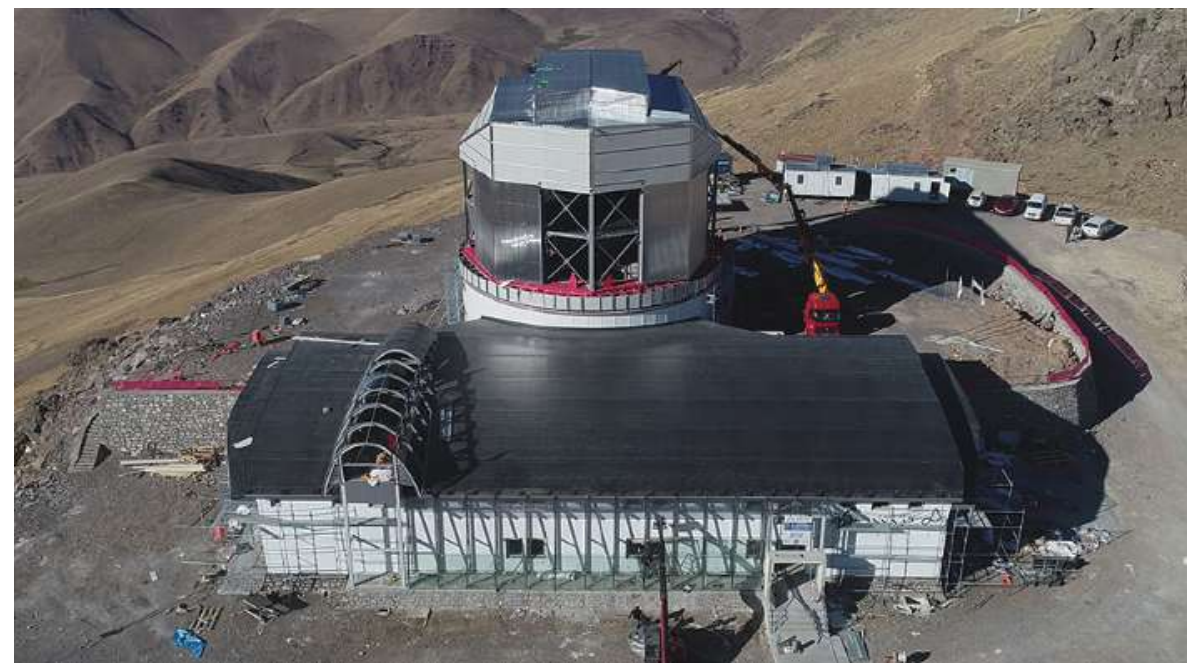

Figure 10: Status of the Eastern Anatolia Observatory (DAG) as of November 2019.

DAG telescope has been manufactured completely in the relevant $A M O S^{8}$ and EIE workshops, dissembled and ready for the transportation to the observatory site in 2020. Following the completion of the enclosure in summer 2020, assembling of the telescope will be started. In the meantime, telescope's M2 and M3 mirrors are ready and packed for the transportation, whereas M1 mirror is in the stage of final coating which will be ended in June 2021.

DAG telescope will be very unique such that a $4 \mathrm{~m}$ Ritchéy-Chretien telescope supported with active and adaptive optics. Adaptive optics facility and the de-rotators of the telescope have been designed and built in FMV Isik University's Optomechatronics Research and Application Center $\left(\mathrm{OPAM}^{9}\right)$ in Turkey and ready to transport to the observatory.

Recently, an article about the current status of the DAG project has been published on the Science $^{10}$ magazine.

\section{Light Pollution Working Group}

In parallel of the efforts building a $4 \mathrm{~m}$ optical+NIR telescope, Turkey also struggles to decrease the light pollution. These efforts especially important for the cities of Antalya and Erzurum, where the TUBITAK National Observatory and the Eastern Anatolia Observatory is located, respectively.

Turkish Astronomical Society took it very serious and established a working group for the light pollution awareness. Light pollution studies in Turkey was first initiated by Prof. Zeki Aslan who is the founder director of the TUBITAK National Observatory. Prof. Aslan is also contributing the TAD's working group as a honorary member.

Light pollution WG aims to create a public awareness and with this support legislation about the illumination can be modified. France's recent law about preventing and decreasing light pollution is very promising. In order to make similar legislation become reality, WG contacted with the Turkish National Committee on Illumination ${ }^{11}$ and both bodies decided to act in cooperation for this purpose.

In a recent astronomical public outreach activity, National Sky Fest (Fisek and Alis, 2020), the Minister of Industry and Technology, Mr. Varank, convinced about the negative effects of light pollution on observatories, especially to TUBITAK National Observatory. Following his affirmative opinion, TAD increase the efforts regarding to prepare a legislation draft for the illumination. President of the Turkish Astronomical Society gave several speeches to the newspapers and TV channels (see Figure 11) in order to attract public interest.

\footnotetext{
${ }^{8}$ https://www.amos.be

${ }^{9}$ http://opam.isikun.edu.tr/en

${ }^{10}$ https://www.sciencemag.org/news/2020/03/we-put-everything-it-modest-telescope-could-have-big-impact-turkishscience

${ }^{11}$ http://www.atmk.org.tr
} 


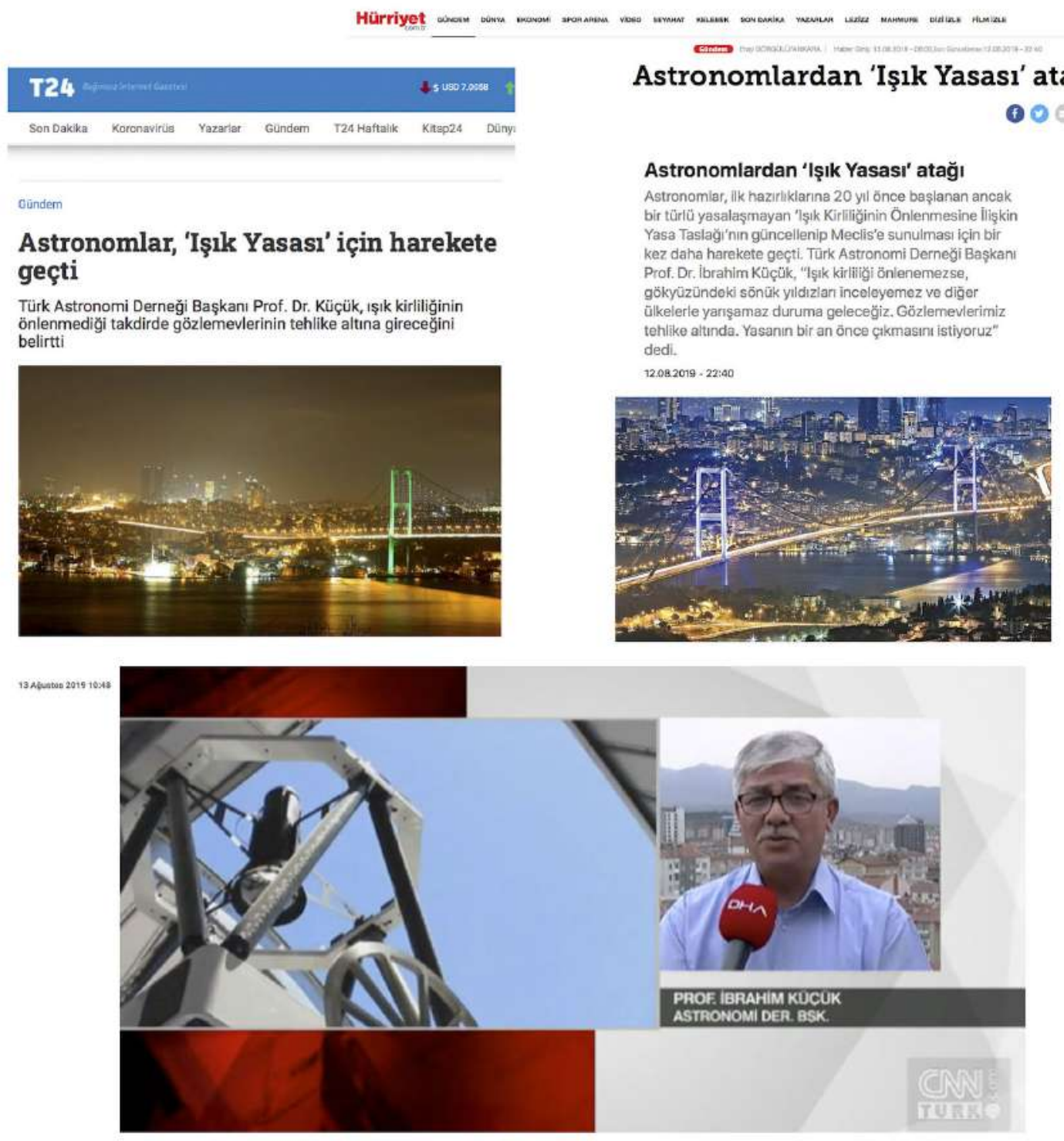

Figure 11: A collage of news about the need and call for a legislation for the light pollution.

\section{Acknowledgements}

Authors are grateful for the hospitality of the Byurakan Astrophysical Observatory staff. Authors acknowledge the support from the IAU South West and Central Asia Regional Office of Astronomy for Development.

\section{References}

Fisek, S. and Alis, S., 2020, ComBAO, 67, 142. 